\title{
Gummy smile: orthodontic or surgical treatment?
}

\author{
E. Izraelewicz-Djebali ${ }^{1,2}$, C. Chabre ${ }^{1,3}$ \\ 1 Docteur en chirurgie dentaire \\ 2 Interne des hôpitaux de Paris \\ 3 Maître de conférences des universités - Praticien hospitalier
}

\begin{abstract} objective in response to patient demand. and surgical. present articles seeks to answer.

\section{KEY WORDS}

Smile, esthetics, orthodontic correction
\end{abstract}

Orthodontists today have to meet their patients' increasing demand for esthetic satisfaction. This quest for youth and beauty is a new development in orthodontics, leading practitioners to try to discern the elements that determine facial esthetics and to set out rules and principles. The essential factor in this demand doubtless concerns a youthful and harmonious smile.

Excessive gingival display in smiling may make the smile displeasing or even repulsive. Correcting "gummy smile" thus becomes a prime treatment

Assessment should therefore seek the etiology of gummy smile, as this will determine optimal treatment, which is usually orthodontic or orthodontic

Which cases call for one approach or the other? This is the question the

\section{INTRODUCTION}

Patients today no longer consult only for functional reasons but increasingly for esthetic reasons, and notably to increase the beauty of their smile. Smiling involves criteria of beauty to which society today gives increasing importance and, while the smile may be a "killer app" for some people, it can constitute a real complex, or indeed a handicap, for others, especially in some forms of "gummy smile".

After detailed analysis of the smile, the present study seeks to identify the causes of gummy smile so as to determine optimal treatment.

\section{SMILING AND ESTHETICS}

The esthetics of smiling basically depends on the relations between three anatomic components: gum, teeth and lips.
- The gum is an important element in the esthetics of smiling; harmony is bound up with several criteria, including 


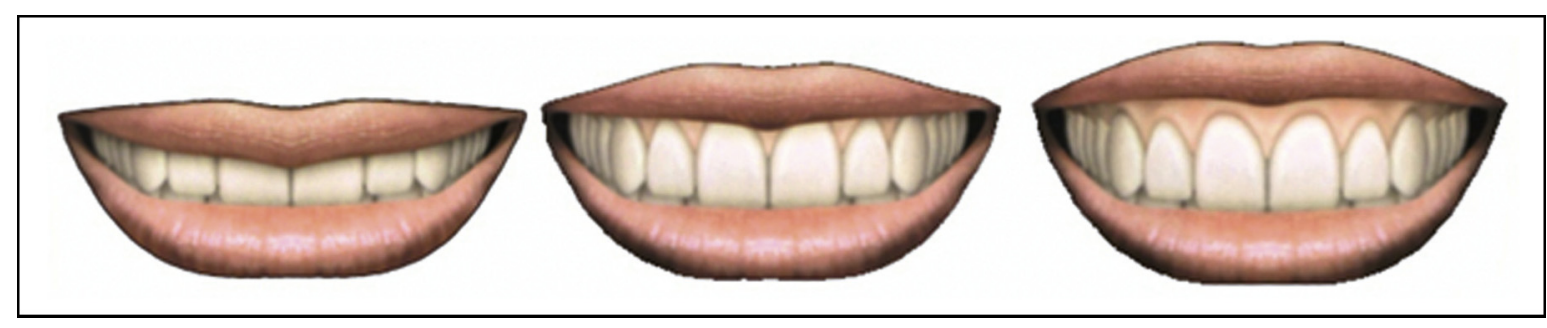

Figure 1

The different types of smile line ${ }^{4}$.

gingival health, the alignment and shape of the tooth necks, an esthetically pleasing gingival line, and a harmonious smile line.

- The teeth also make an important contribution to the sense of harmony of the face and smile, depending on their size, shape and color, but also on arcade symmetry, which is an aspect of overall intra- and inter-arcade relations.

- The lips are the third essential component having a major impact on the beauty of the smile, as they delimit the esthetic area ${ }^{2}$. Their inter-relation and length greatly determine the amount of teeth and gums exposed during smiling.

The smile line is primordial. There are three main types ${ }^{23,9}$ :

- a low smile line, exposing less than $75 \%$ of anterior maxillary coronary height; this patterns predominates in males;

- a medium line, exposing 75$100 \%$ of anterior maxillary coronary height and the interproximal gum;

- and a high line, exposing the entire coronary height and a continuous band of gum. This is the pattern that will particularly interest us here, as this is the socalled "gummy smile" (Fig. 1).

It may be wondered which elements go to making a smile "beautiful". According to Miller, the following characteristics are required $^{12}$ :

- the marginal gum along the maxillary teeth should follow the shape of the upper lip, while the incisor edge of the anterior teeth should tend to follow the shape of the lower lip;

- the marginal gum should be symmetrical between left and right;

- the central incisors and canines should be of the same length (about $13 \mathrm{~mm}$ ) and the lateral incisors should be 1 or $2 \mathrm{~mm}$ shorter;

- the line of the upper lip should touch the marginal gum of the central incisors and canines and the lower lip should touch the incisor edge of the 6 anterior maxillary teeth;

- tooth dimensions should reflect the "golden number" of esthetics ${ }^{8}$.

\section{When is a smile "gummy"?}

According to Allen, a smile is said to be gummy if more than 2 or 

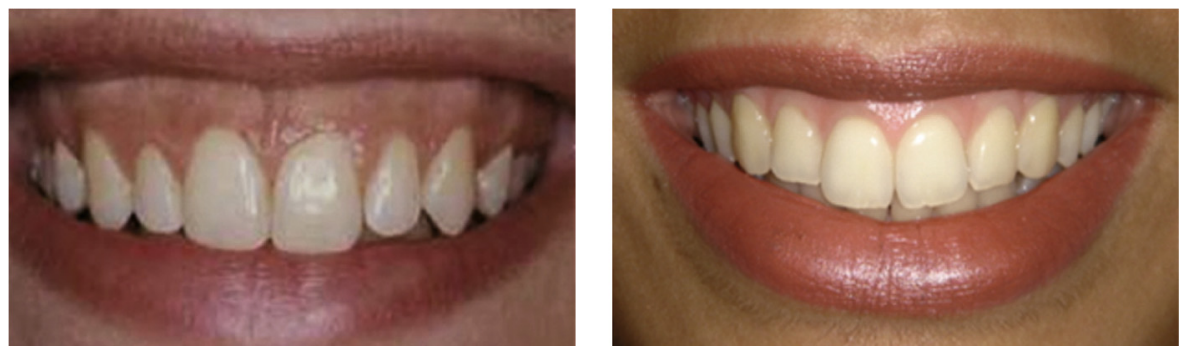

Figure 2

Harmonious gummy smiles ${ }^{9}$.

$3 \mathrm{~mm}$ of gum is visible during sustained smiling; this is confirmed on forced smiling ${ }^{2}$.

Gummy smiles are not necessarily esthetically displeasing if certain rules of harmony are respected: it is not the excess soft tissue in itself that is displeasing, but rather its relation with the teeth and lips (Fig. 2).

It is thus up to the patient to decide whether his or her gummy smile looks displeasing.

\section{How to diagnose gummy smile?}

Gummy smile is fairly easy to diagnose; determining its causes, on the other hand, is more complicated. For this reason, complete diagnosis is required, to determine not only facial and oral but also cephalometric characteristics.

\section{ETIOLOGY OF GUMMY SMILE}

It is essential to determine the etiology of a gummy smile in order to optimize treatment. There are three main etiologies, which may in some cases be combined.
Many authors have tried to define normality in the esthetics of the smile and face. The smile cannot be considered apart from the surrounding face, nor the face without the smile. Esthetic assessment is important to selecting treatment objectives ${ }^{7}$.

After examining all the components of the face, the practitioner focuses on intraoral examination, analyzing the various smile components, and especially the teeth and periodontium.

Although clinical analysis is primordial in gummy smile, radiography enables:

- skeletal etiology to be confirmed;

- the occlusion plane and the orientation of the palatine plane to be analyzed;

- and dental-labial relations to be assessed.

\section{Cutaneo-mucosal origin}

To analyze this form, the patient needs to be examined at rest, to assess upper lip length. 


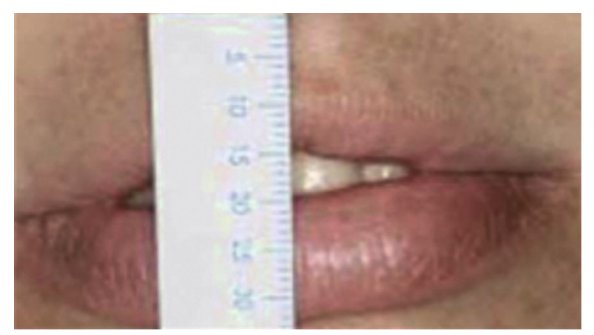

Figure 3

Girl with thin (15 mm) upper lip $^{22}$.

Cutaneo-mucosal etiology is revealed by various factors:

- upper lip length, considered thin if $<20 \mathrm{~mm}^{25}$, increasing the visibility of the teeth at rest (Fig. 3);

- another cause may be upper lip levator muscle hypertonicity during smiling, leading to excessive gum exposure (Fig. 4).

According to Peck and Peck, subjects with gummy smile have more effective upper lip muscles ${ }^{13}$.

\section{Dento-periodontal origin}

Secondly, there are three forms of dento-periodontal etiology:

- abnormal maxillary incisor size, with clinically short crowns due to relative microdontia or bruxism; the gum exposed during smiling looks all the greater in comparison with the shortness of the incisors;

- gingival hypertrophy and hyperplasia, defined as abnormal hypertrophic development of the gum, especially at the interdental papillae, covering part or even all of the crown, with esthetically displeasing results ${ }^{2}$;

- finally, impaired passive eruption is an abnormality of dental developmental, which is arrested or delayed $^{2}$.

Gum tissue is then in a coronary position with respect to the enamelcement junction, inducing pronounced gummy smile and short, square teeth.

In all the above situations, the amount of gum exposed in smiling appears greater if the incisors are
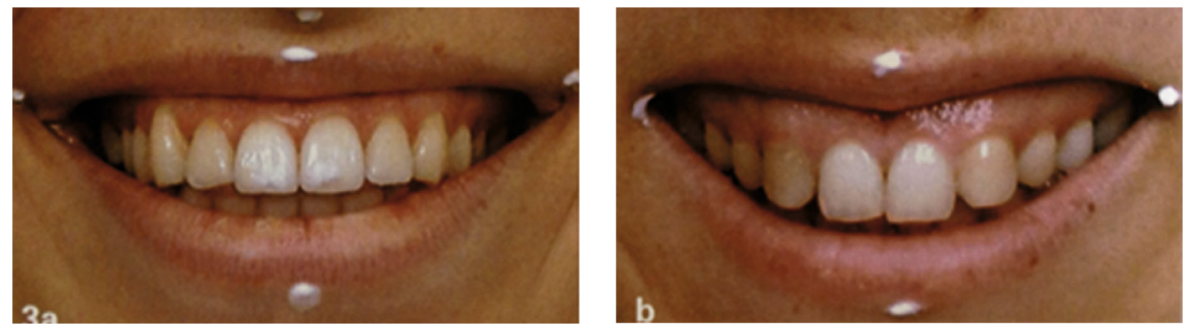

Figure 4

Gummy smiles of muscular origin. 
short, creating an unfavorable gum/ crown ratio with excessive gum exposure.

\section{Alveolo-skeletal origin}

Most often, however, gummy smile is of alveolo-skeletal origin: basal, alveolar or a combination of the two. This is due to excessive vertical growth of the maxilla or superior alveolar bone, causing discrepancy between the upper lip and gum line in spontaneous smiling. This is the most common etiology ${ }^{1}$.

It may be related to superior labioversion, an anteroposterior abnormality localized at the incisors, with excessive vestibular inclination of the teeth. This leads to dento-mucosal sliding of the upper lip, revealing a wide band of gum? ${ }^{7}$.

It may also be due to anterior maxillary dento-alveolar protrusion, due to over-eruption of the maxillary incisors and their dento-gingival complex. This is usually caused by anterior supra-occlusion, with discordance between the occlusion planes of the anterior and posterior sectors.

This etiology should be differentiated from occlusion plane tilt, assessed on lateral teleradiograph.

The other possible etiology is excessive vertical maxillary growth, usually associated with so-called "long face" syndrome. Occlusion

\section{TREATMENT OF GUMMY SMILE}

Treatment options for excessive gum exposure in smiling depend on the specific diagnosis.

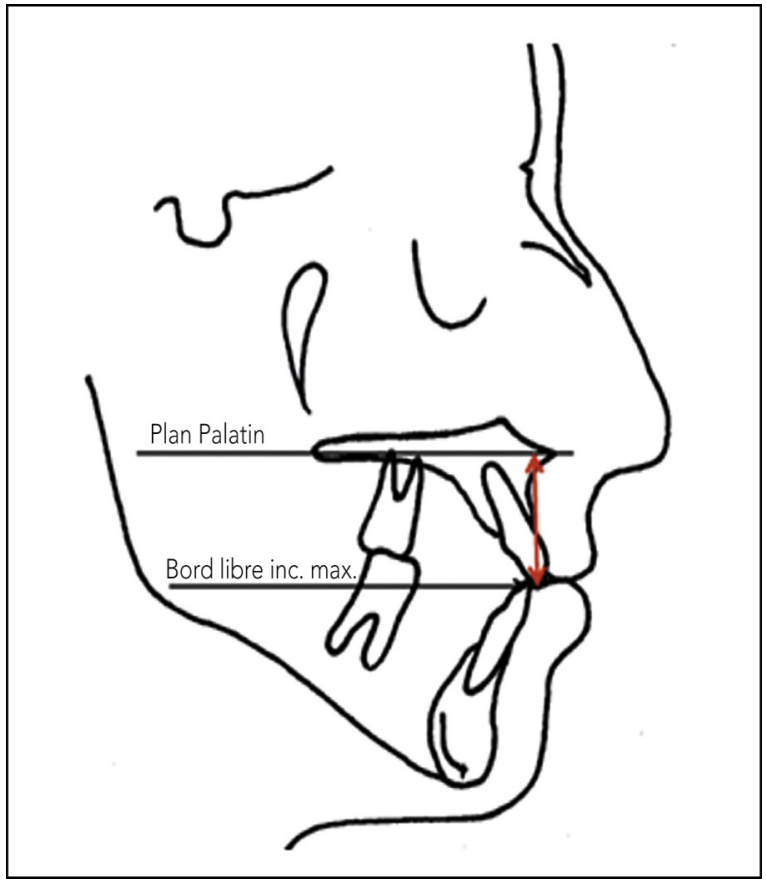

Figure 5

Cephalometric analysis: anterior maxillary height is measured between the palatine plane and the free edge of the superior maxillary incisor.

analysis usually finds Angle class II malocclusion, sometimes associated with a gap or supra-occlusion due to dento-alveolar compensation.

According to Peck et al. ${ }^{13}$, the distance between the palatine plane and the free edge of the maxillary incisors has been shown to be about $2 \mathrm{~mm}$ greater in gummy smile than in controls (Fig. 5).

As seen above, etiology is varied, and treatment has to take account of this (Fig. 6). 


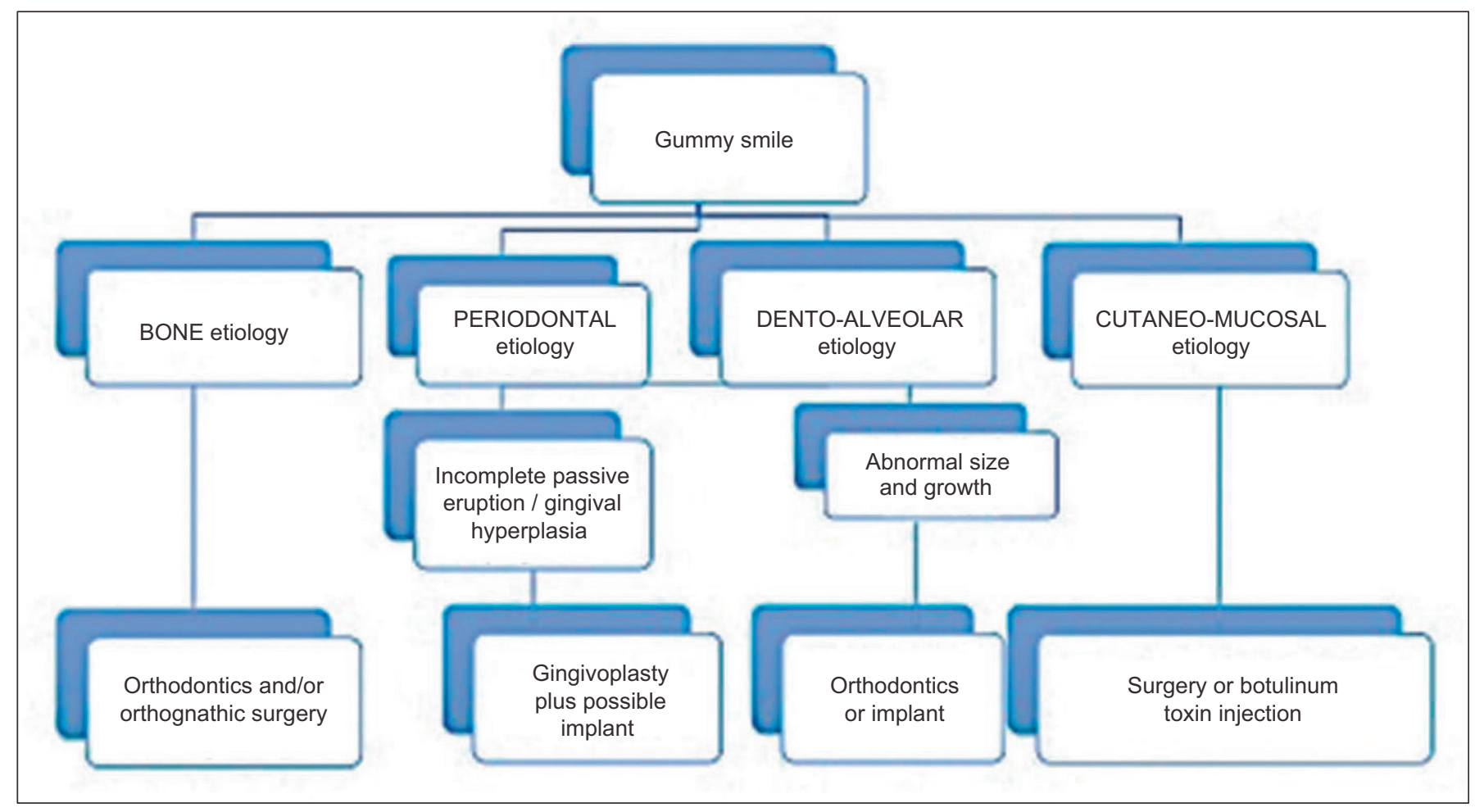

Figure 6

Treatment flowchart according to etiology.

As mentioned in the Introduction, gummy smile is not necessarily displeasing and in some cases abstention may be the attitude of choice; likewise if the patient is not motivated or cooperative.

In all other situations, adapted treatment should be planned.

\section{Surgical treatment for gummy smile of cutaneo-mucosal origin}

In cutaneo-mucosal etiologies, reconstruction surgery of the soft tissue, and notably of the upper lip, may correct gummy smile. Whatever the abnormality of the lip, the objective is to weaken the lip levator muscles to achieve a more coronary position and reduce gum expose ${ }^{1}$.

More recently, type A botulinum toxin injection, essentially described by Polo in 2005, has provided a nonoperative solution. Reduced exposure is obtained by weakening upper-lip levator muscle contractility. This is reversible, and injection has to be renewed $^{16,17}$.

\section{Treatment for gummy smile of dento-periodontal origin}

In dento-periodontal etiologies, periodontal treatment can harmonize the contour of the gum, with or without associated implantation. 


\section{- Periodontal treatment}

Periodontal treatment alone cannot meet patient expectations unless gum exposure is mild: for example, in case of impaired passive eruption or gingival hyperplasia, where periodontal treatment is very appropriate.

Coronary lengthening (of the clinical crown) may be achieved either by gingivectomy by internal beveling or by an apical flap, with or without bone resection.

More recently, developments in laser surgery have simplified what could be heavy procedures, thereby extending indications ${ }^{19-21}$.

\section{- Implantation}

In gummy smile caused by abnormal tooth size, with well-positioned gum, implantation is required to achieve clinical coronary lengthening ${ }^{1}$, and should be considered in case of:

- clinically short crown;

- defective repair or esthetic complaint;

- or root exposure following periodontal treatment, inducing hypersensitivity in the teeth.

\section{Orthodontic treatment in gummy smile of alveolar origin}

Correcting gummy smile may be an especially complex objective for the orthodontist. Only moderate gummy smile of alveolar origin responds to isolated orthodontic treatment. Gummy smile of alveolar origin is generally associated with supra-occlusion limited to the incisor group. In vertically normal gummy smile, intrusion of the maxillary incisors is the treatment of choice $^{15}$.

Moreover, except in particularly severe cases, gummy smile is rarely the prime target of orthodontic treatment. Rather, it is usually associated to correction of malocclusion, determining the treatment plan ${ }^{8}$.

Treatment can be undertaken at a very early age to prevent onset of supra-occlusion ${ }^{14}$. Once gummy smile has emerged, there are orthodontic mechanisms to improve the relation between upper lip and teeth, reducing gum exposure.

Conventional techniques can be used: e.g., Ricketts' basal arch to achieve superior incisor intrusion ${ }^{7}$.

This intrusion, however, is difficult to obtain and is often accompanied by molar extrusion, which may not be desired, especially in hyperdivergent subjects with gummy smile.

More recently, the development of mini-screw bone anchors has extended the possibilities of orthodontic treatment: anterior vertical excess found in adults can now be corrected by intrusion, limiting unwanted sideeffects in the posterior sectors by appropriate mini-screw positioning $^{15,11,24}$ (Fig. 7).

This technique is increasingly used to correct gummy smile in adults, as mini-screws combine several advantages:

- easy of fitting and ablation;

- immediate implementation;

- patient comfort;

- relatively low cost ${ }^{15,24}$.

It is an interesting alternative to the risks and demands of orthognathic 


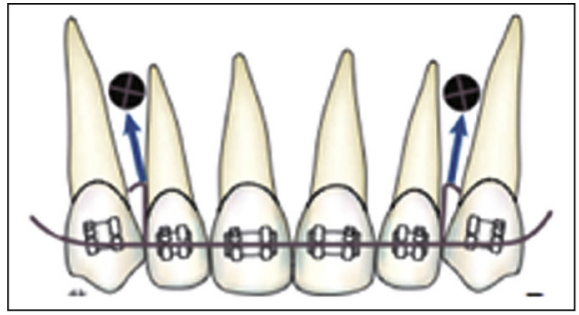

a

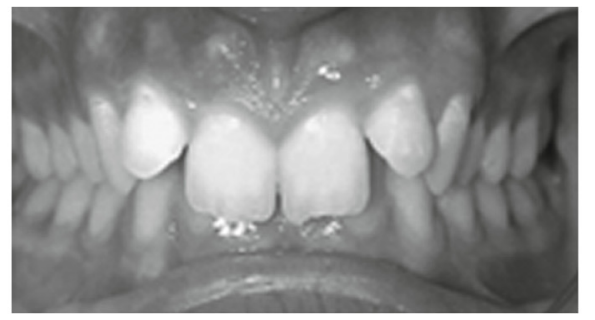

Figure 7

(a) Diagram of incisor intrusion using mini-screws ${ }^{11}$, and (b) treatment of supra-occlusion by mini-screw anchorages $^{15}$.

surgery, the previous attitude of choice.

\section{Orthodontic-surgical treatment of gummy smile of skeletal origin}

In some cases, isolated orthodontic treatment will not be enough to correct large excess anterior gum exposure, especially when of skeletal

\section{DATA ANALYSIS FROM CASE REPORTS}

To illustrate the above, we report two cases managed using different treatments, according to the etiology of the gummy smile:

- orthodontic treatment for alveolar etiology;

- orthodontic plus surgical treatment for skeletal etiology.

\section{Method of analysis}

To analyze the effects of different treatments, measurements were made on pre- and post-treatment lateral teleradiographs in the two patients:

- Esthetically, distance between the free edge of the superior

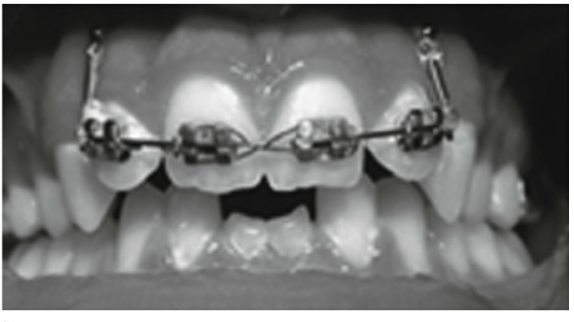

b 


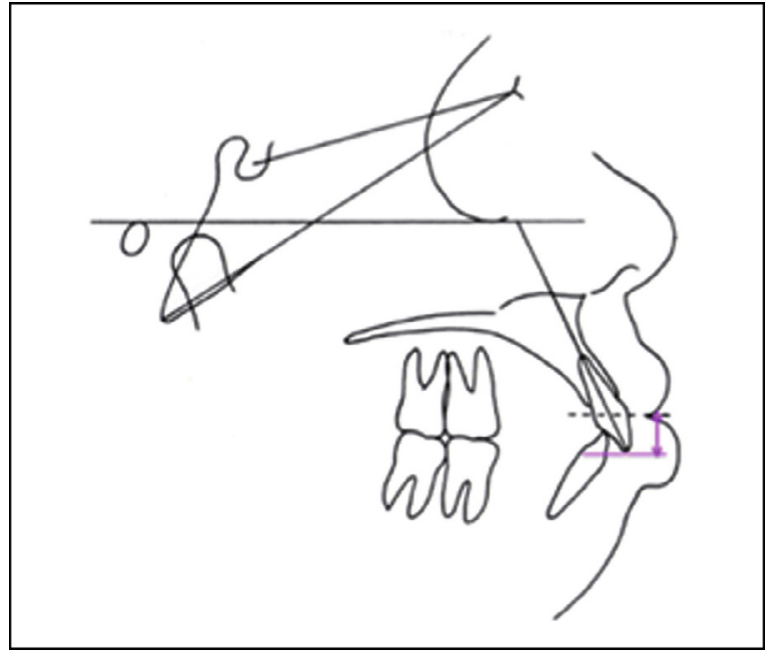

Figure 8

Measurement of distance between free edge of the superior incisor and stomion.

- Skeletally, movement in the palatine plane, measuring:

- Angles between palatine plane and nasion-basion and sella turcica-basion reference planes, to assess any palatine plane tilt;

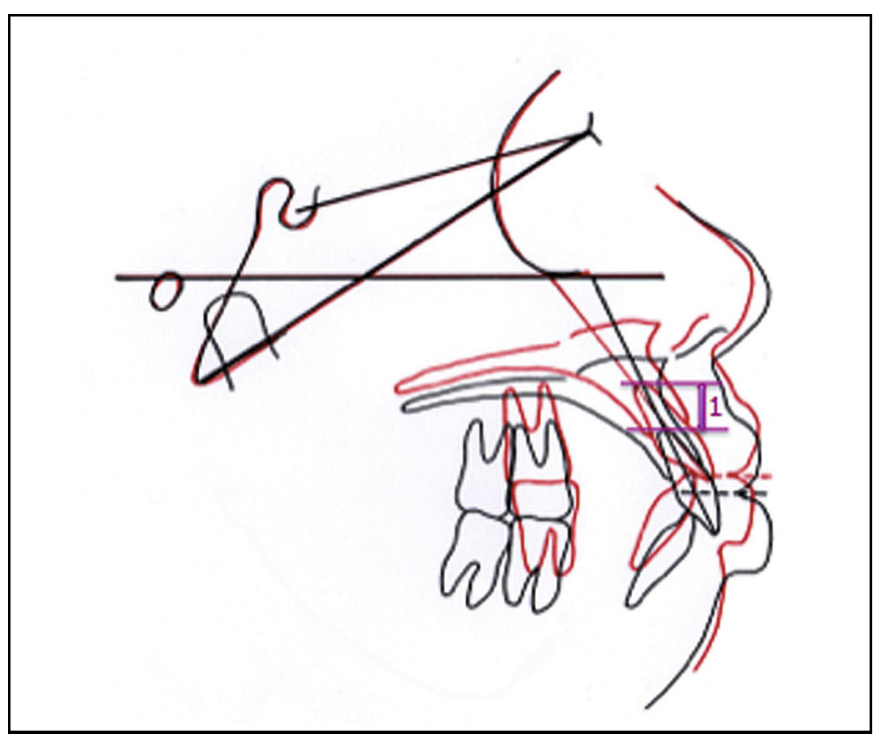

- Distance between ENA and ENP points and Frankfurt plane, pre- and post-treatment (Fig.10).

\section{Gummy smile of alveolar origin treated orthodontically (Chabre)}

Morgane C., aged 13 years, presented with a harmonious face externally, but fairly severe lingual version of the maxillary incisors (Fig. 11). Intraorally, she showed Angle class I molar and canine class II relationships, with severe anterior crowding, supra-occlusion and Spee's curvature (Fig. 12).

After analysis of panoramic and lateral radiographs and $3 \mathrm{D}$ models, and given the reasons for consultation, maxillary incisor intrusion was chosen to correct the gummy smile, associated to premolar extraction in both arcades (14/24-34/44) to correct crowding and the curve of Spee.

Figure 9

Dento-alveolar effects of treatment. 


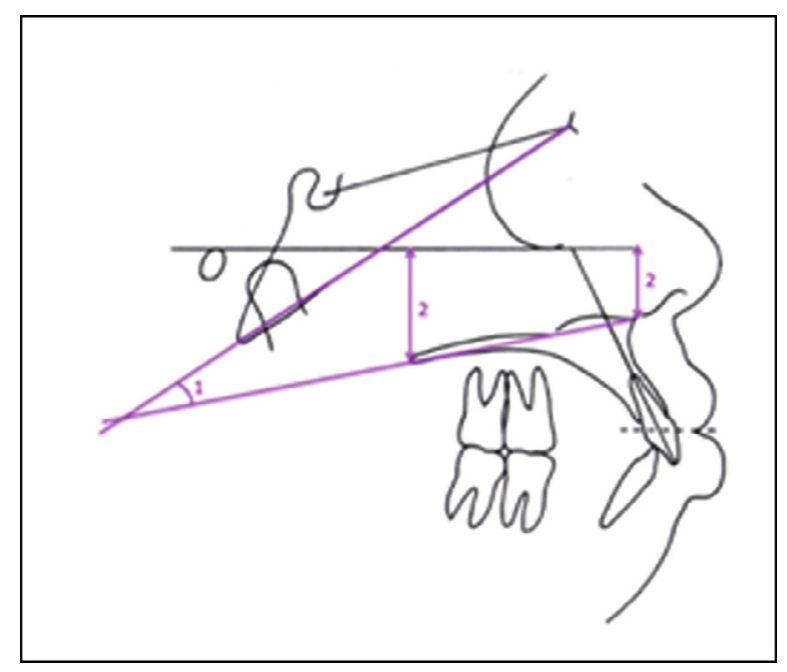

Figure 10

Skeletal effects of treatment.

A fixed multi-attachment device was fitted, with a segmented Ricketts mechanism, using a basal intrusion arch and T-loops to draw back the canines (Fig. 13).

Effects were analyzed on pre- and post-treatment lateral teleradiographs and general superimpositions on the Frankfurt plane (Fig. 14).

Multi-ring treatment using a segmented technique was able to correct the patient's gummy smile, limited to the incisors, by pure orthodontic incisor intrusion (Fig. 15).

The cephalometric measurements confirmed that:

- esthetically, intrusion improved the position of the maxillary incisor with respect to the stomion, as seen on external photographs of the smile at end of treatment;

- in dento-alveolar terms, not only intrusion but significant vestibular version of the superior incisor was obtained by radiculo-palatine torque, helping improve the incisor axis;

- skeletally, following treatment there was no tilt but only lowering of the palatine plane, related to growth, partly masking the dento-alveolar effects.
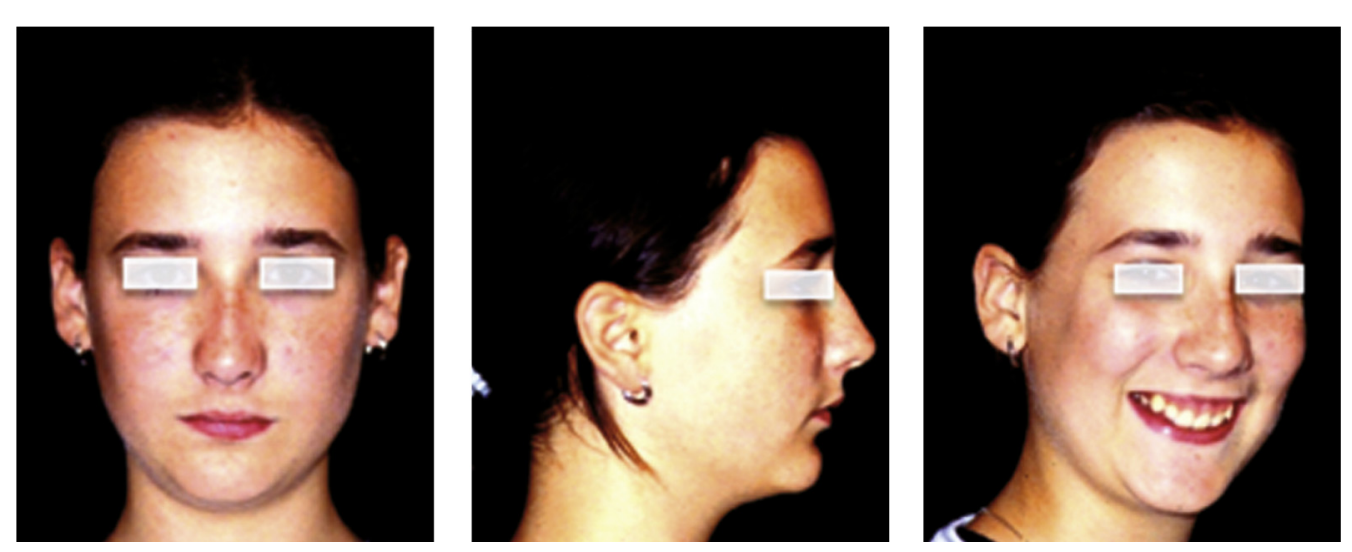

Figure 11

Pre-treatment external photographs. 

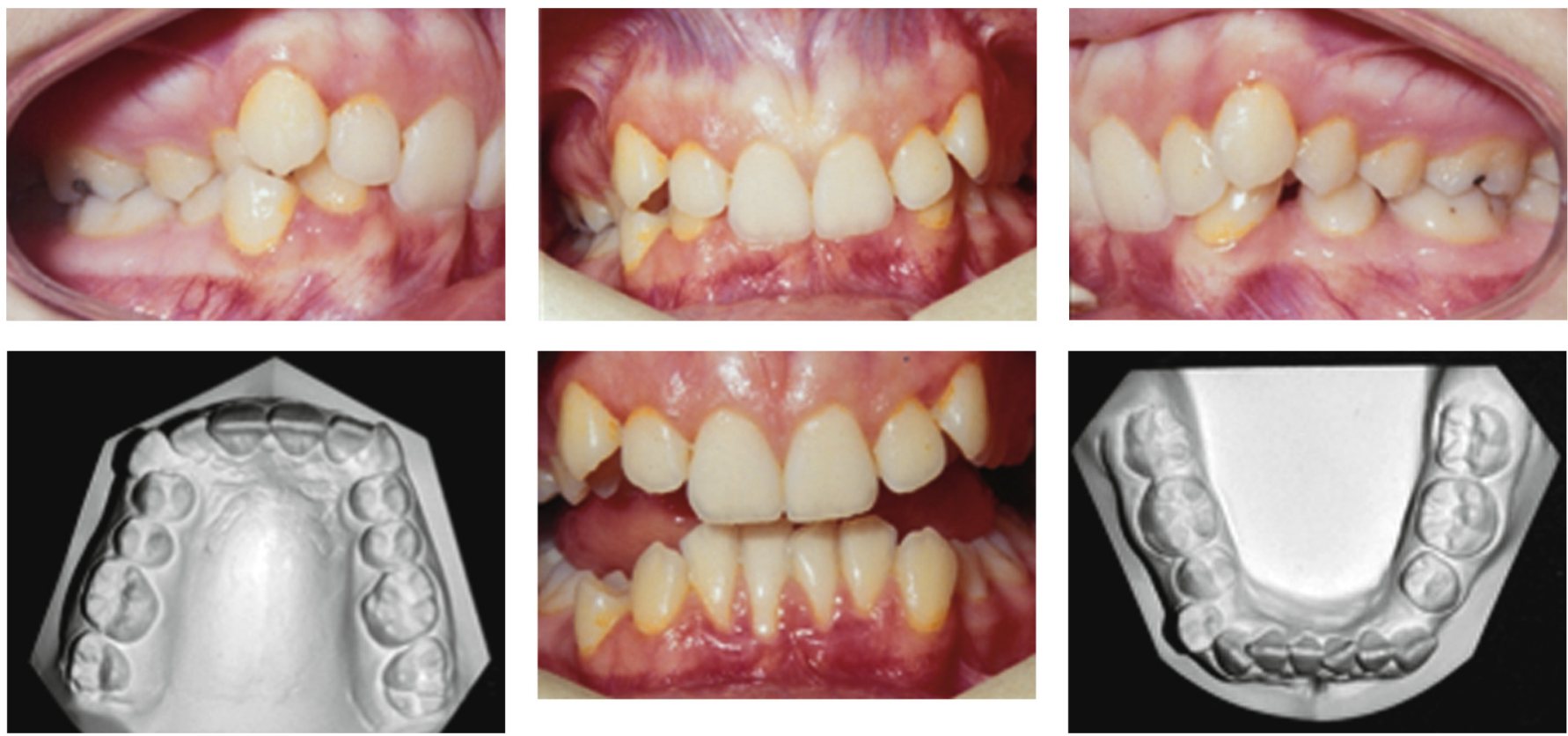

Figure 12

Pre-treatment intra-oral photographs and 3D models.
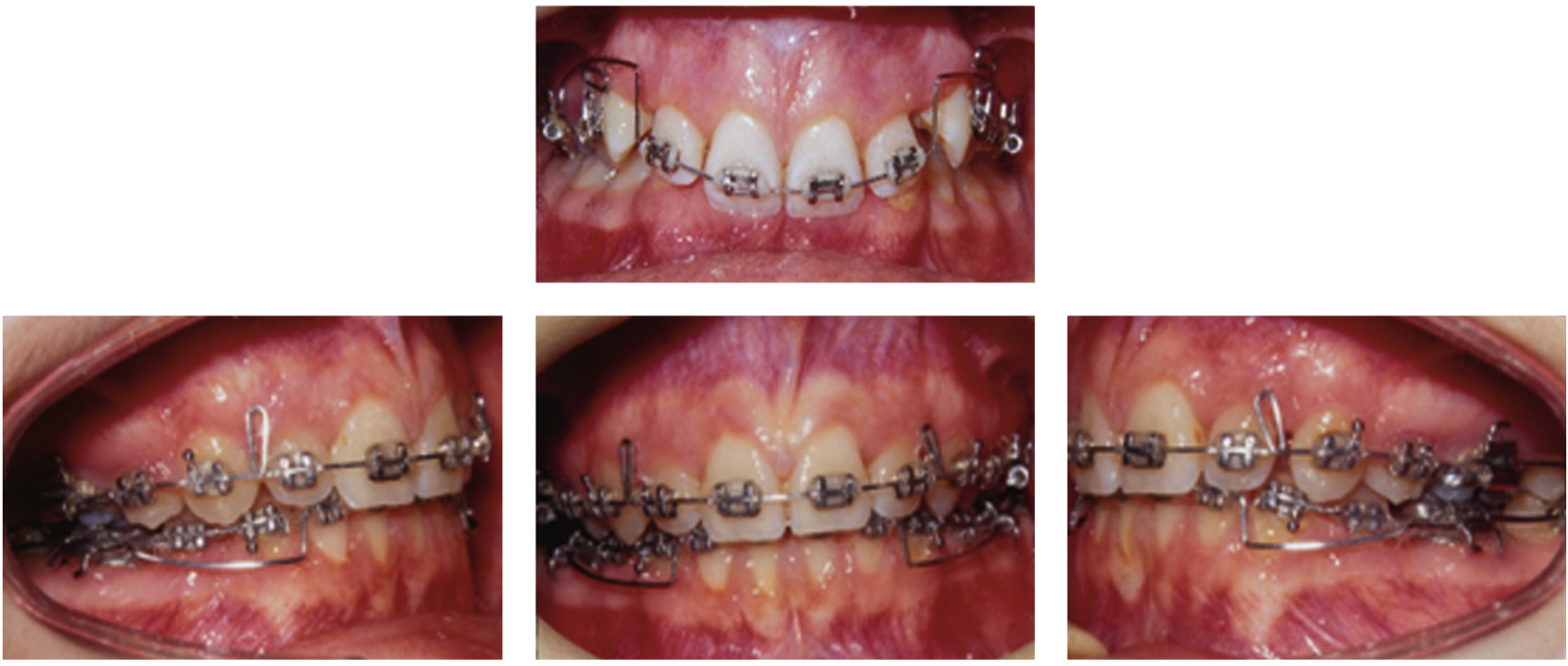

Figure 13

Intra-oral photographs during treatment. 

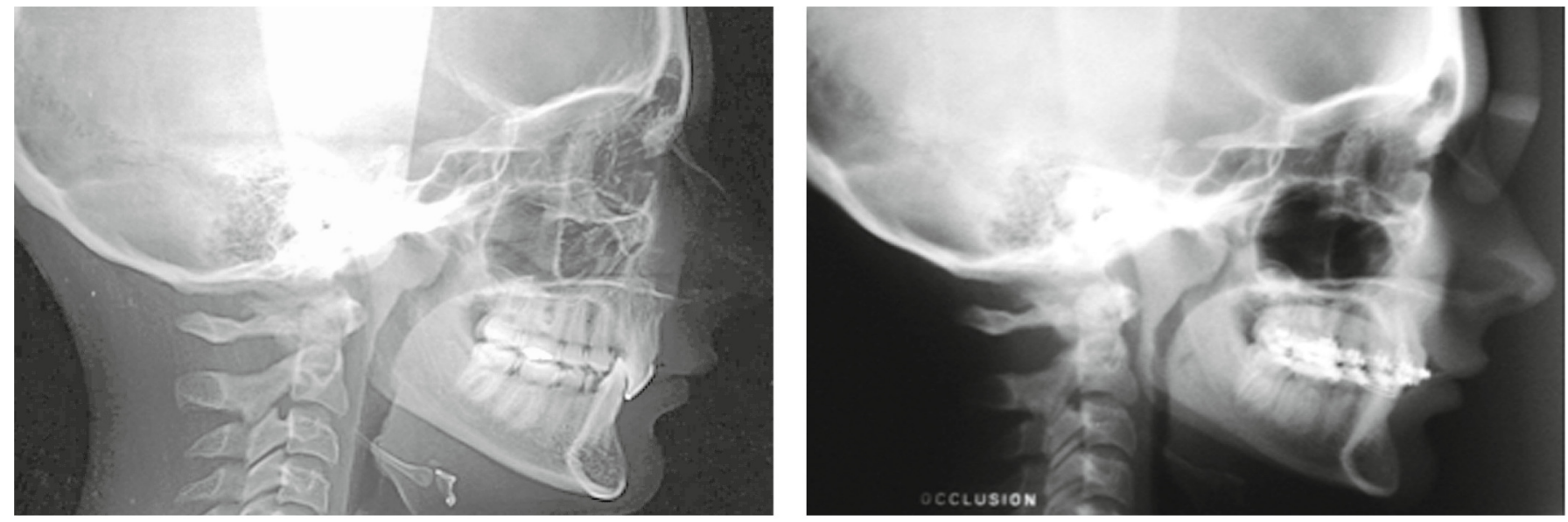

a

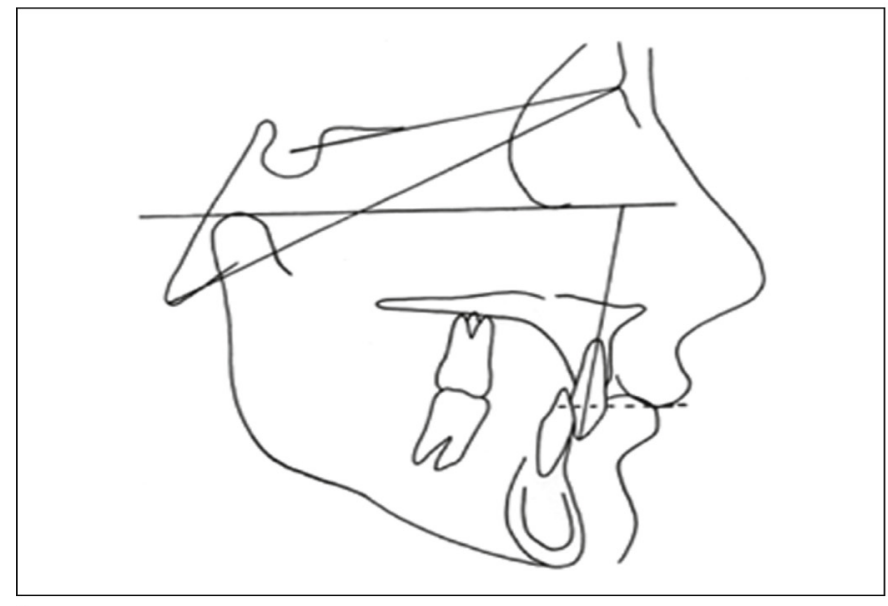

C

b
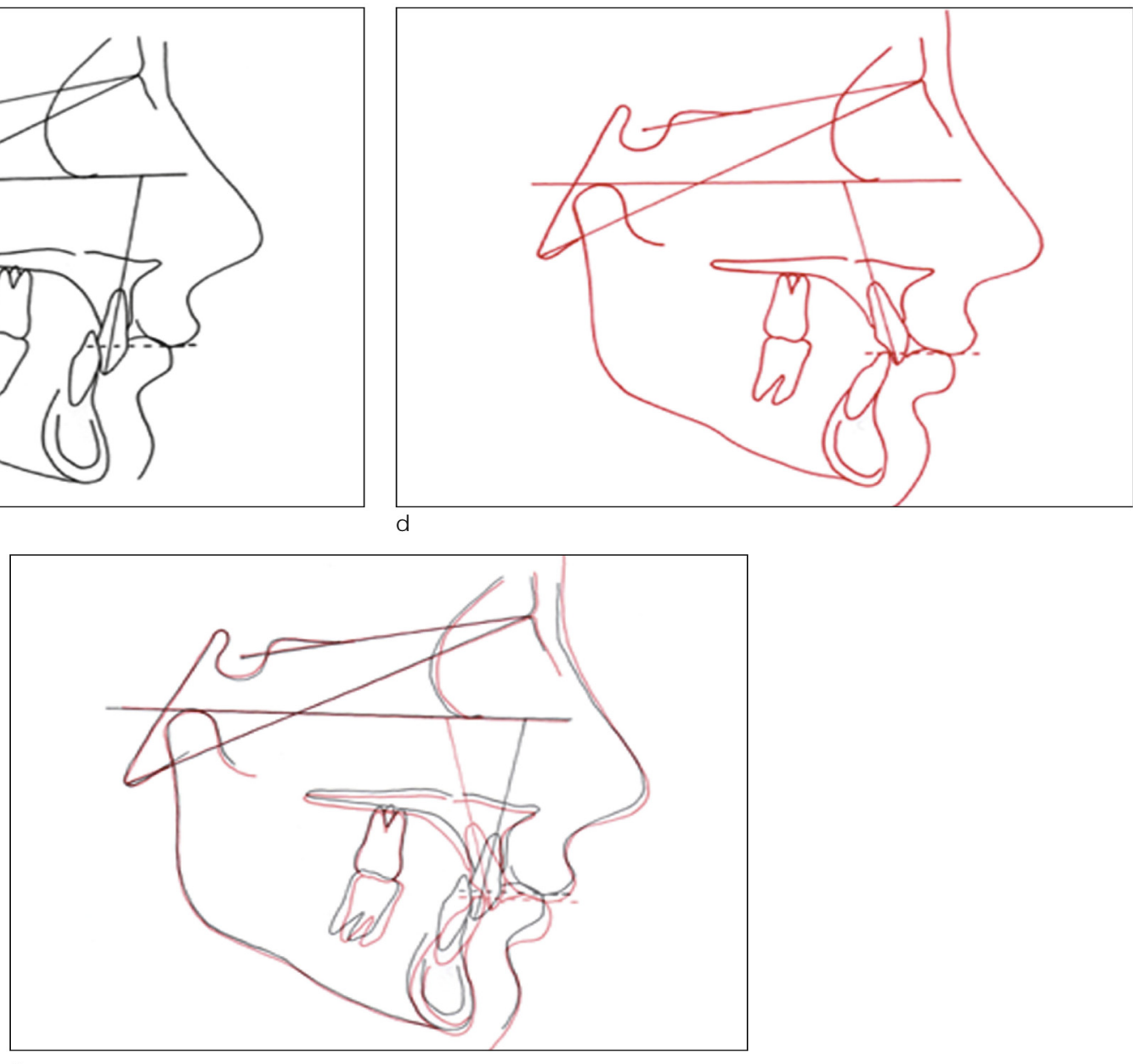

Figure 14

Lateral teleradiographs (a) before and (b) after orthodontic treatment; drawings at (c) start and (d) end of treatment; and (e) general superimpositions in the Frankfurt plane. 


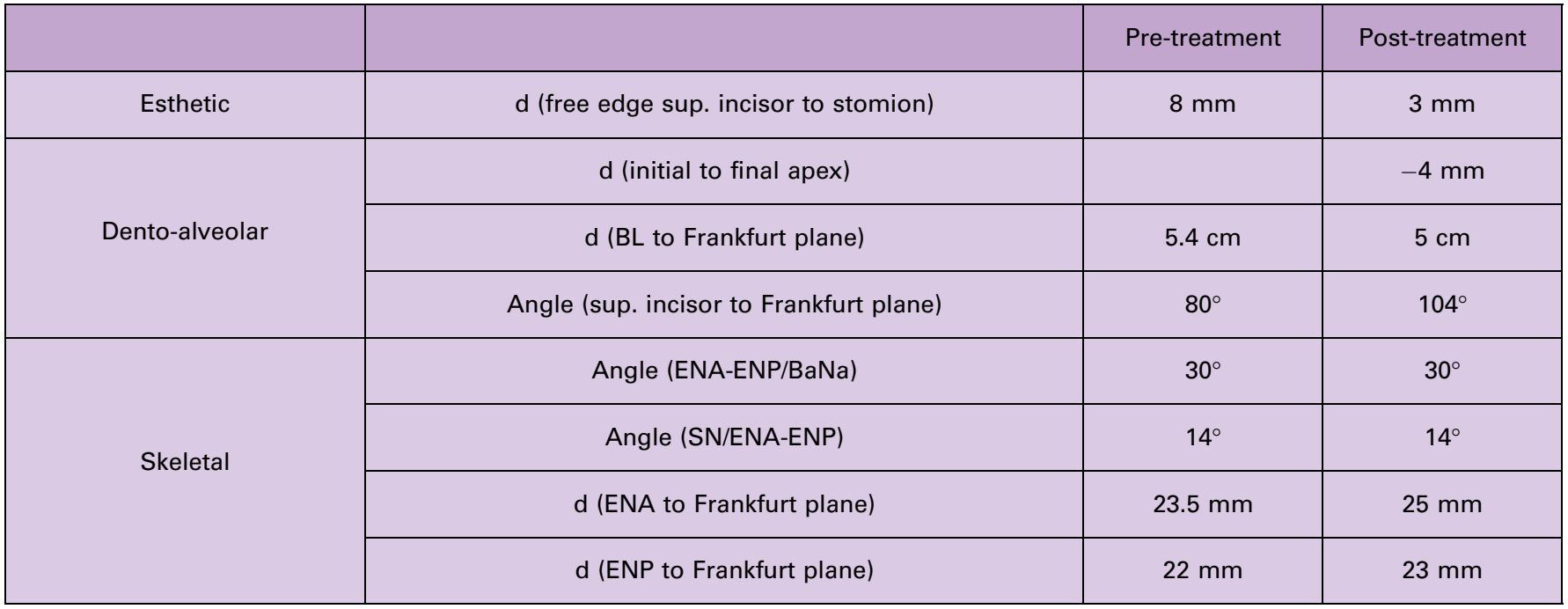

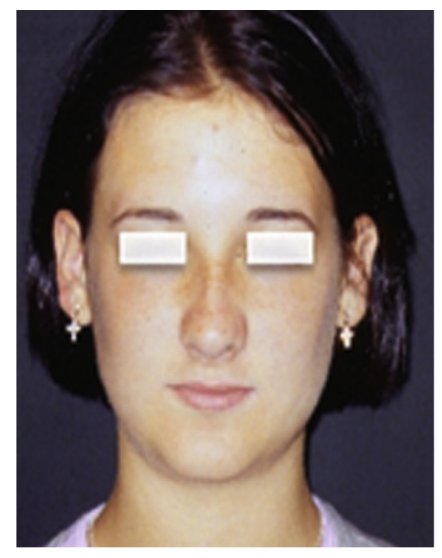

a

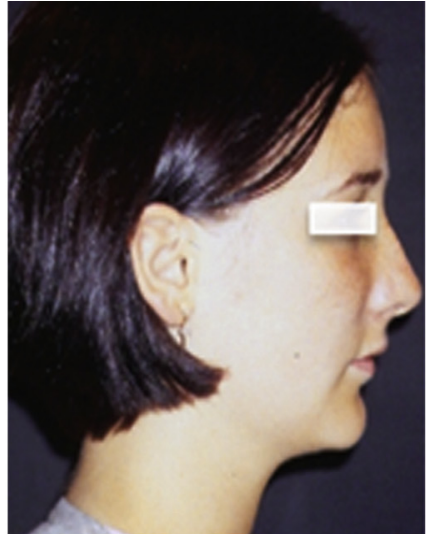

b

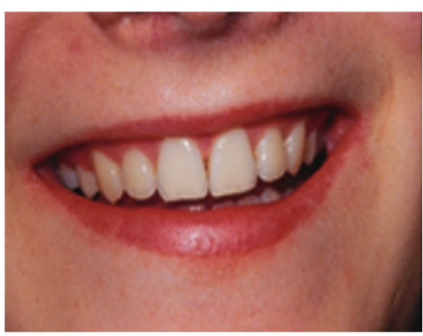

d

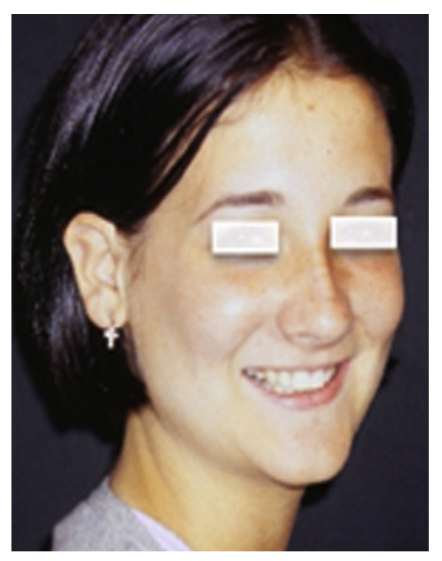

C

Figure 15

$(a, b, c)$ External photographs and (d) smile at end of treatment. 


\section{Gummy smile of skeletal origin, managed by orthodontics and orthognathic surgery (Bedar and Charrier)}

The second case is that of Ms M., aged 26 years, who consulted for purely esthetic reasons, as she loathed her own smile.

She presented with a lengthened face and labial intra-occlusion at rest, revealing the maxillary incisor group and showing a generally convex profile. Examination of her smile, which was the focus of interest, found it disharmonious, revealing a band of gum of about $11 \mathrm{~mm}$ all along the arcade: i.e., "gummy" smile (Fig. 16).

Intraorally, there was no major occlusion abnormality, and notably no supra-occlusion, with Angle class I but very significant anterior vertical excess (Fig. 17).

After complete analysis of the orthodontic file, orthodontic plus surgical treatment was planned in agreement with the maxillofacial surgeon: multi-attachment treatment to align the maxillary and mandibular arcades ahead of bimaxillary osteotomy associated to genioplasty.

As in the previous case, treatment effects were assessed in esthetic, dento-alveolar and skeletal terms, on pre- and post-treatment lateral teleradiographs (Fig. 18).

In this patient:

- Esthetically, significant "intrusion" of the maxillary incisors can be seen on external photographs of the smile at end of treatment. The 11-mm gum band has been reduced to $3 \mathrm{~mm}$ after orthodontic-surgical treatment. The surgeon deliberately left this 3-mm band, to allow for softtissue weakening with age. Moreover, as maxillary impaction surgery affects the nose, enlarging the wings, this had to be controlled according to the patient's baseline morphology.

- In dento-alveolar terms, not only intrusion but significant vestibular version of the superior incisors was obtained with respect to the displacement of the maxilla as a whole.
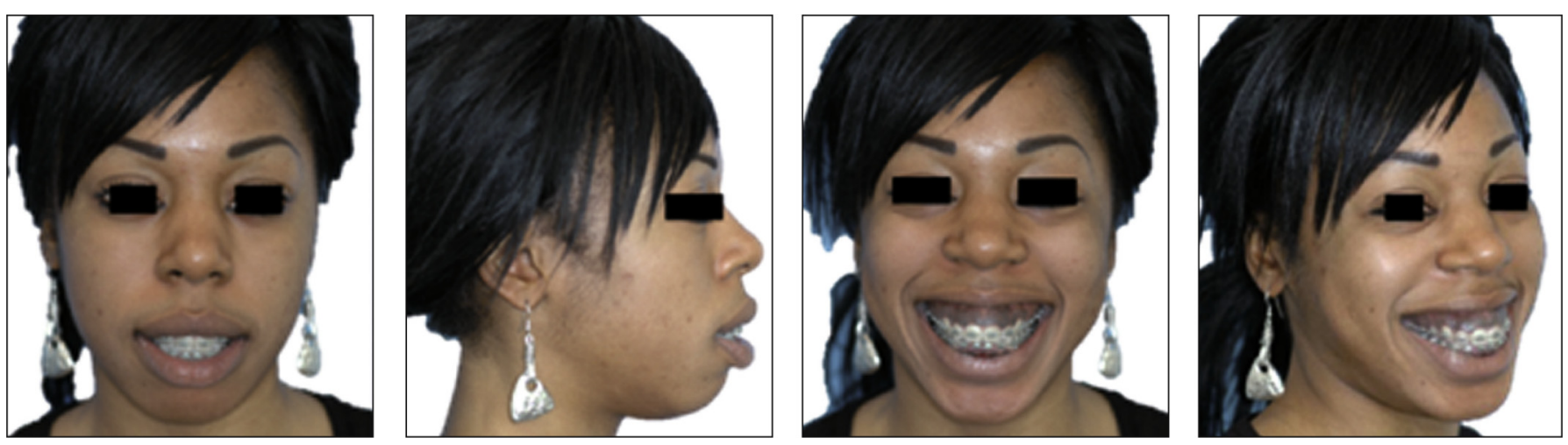

Figure 16

External photographs. 

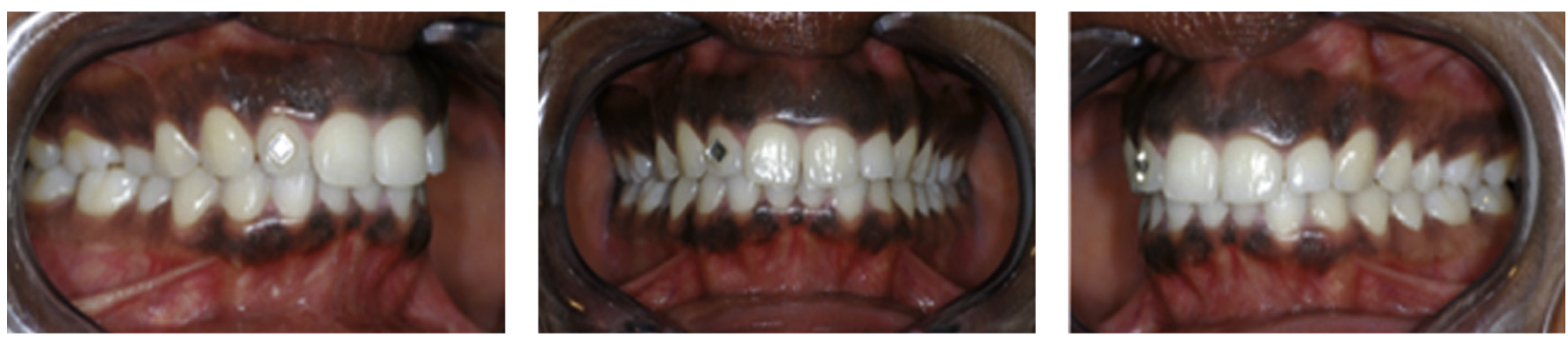

a

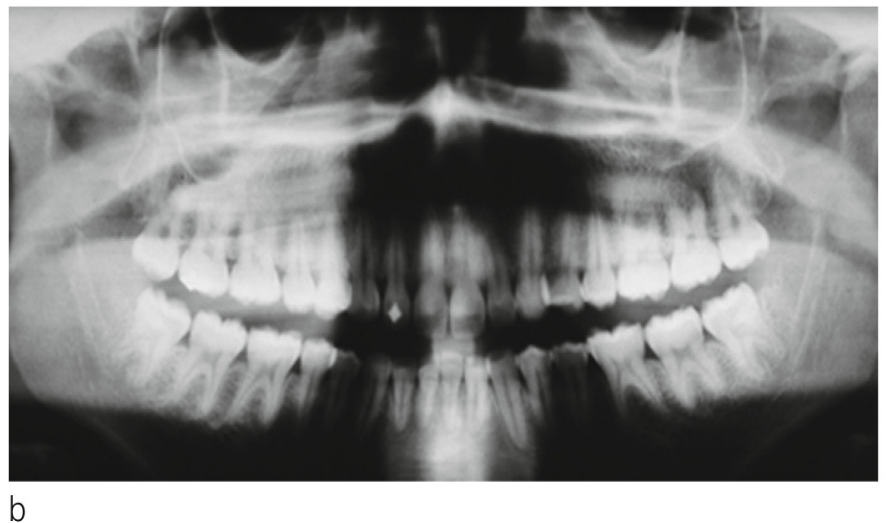

Figure 17

(a) Intraoral photographs; (b) pre-treatment panoramic radiograph.

\begin{tabular}{|c|c|c|c|}
\hline & & Pre-treatment & Post-treatment \\
\hline Esthetic & d (free edge sup. incisor to stomion) & $7 \mathrm{~mm}$ & $1 \mathrm{~mm}$ \\
\hline \multirow[b]{2}{*}{ Dento-alveolar } & d (initial to final apex) & & $-6.5 \mathrm{~mm}$ \\
\hline & $\mathrm{d}$ (BL to Frankfurt plane) & $5.175 \mathrm{~cm}$ & $4.44 \mathrm{~cm}$ \\
\hline \multirow{3}{*}{ Skeletal } & Angle (ENA-ENP/BaNa) & $23^{\circ}$ & $20^{\circ}$ \\
\hline & Angle (SN/ENA-ENP) & $5.5^{\circ}$ & $3.5^{\circ}$ \\
\hline & d (ENA to Frankfurt plane) & $17 \mathrm{~mm}$ & $11 \mathrm{~mm}$ \\
\hline
\end{tabular}



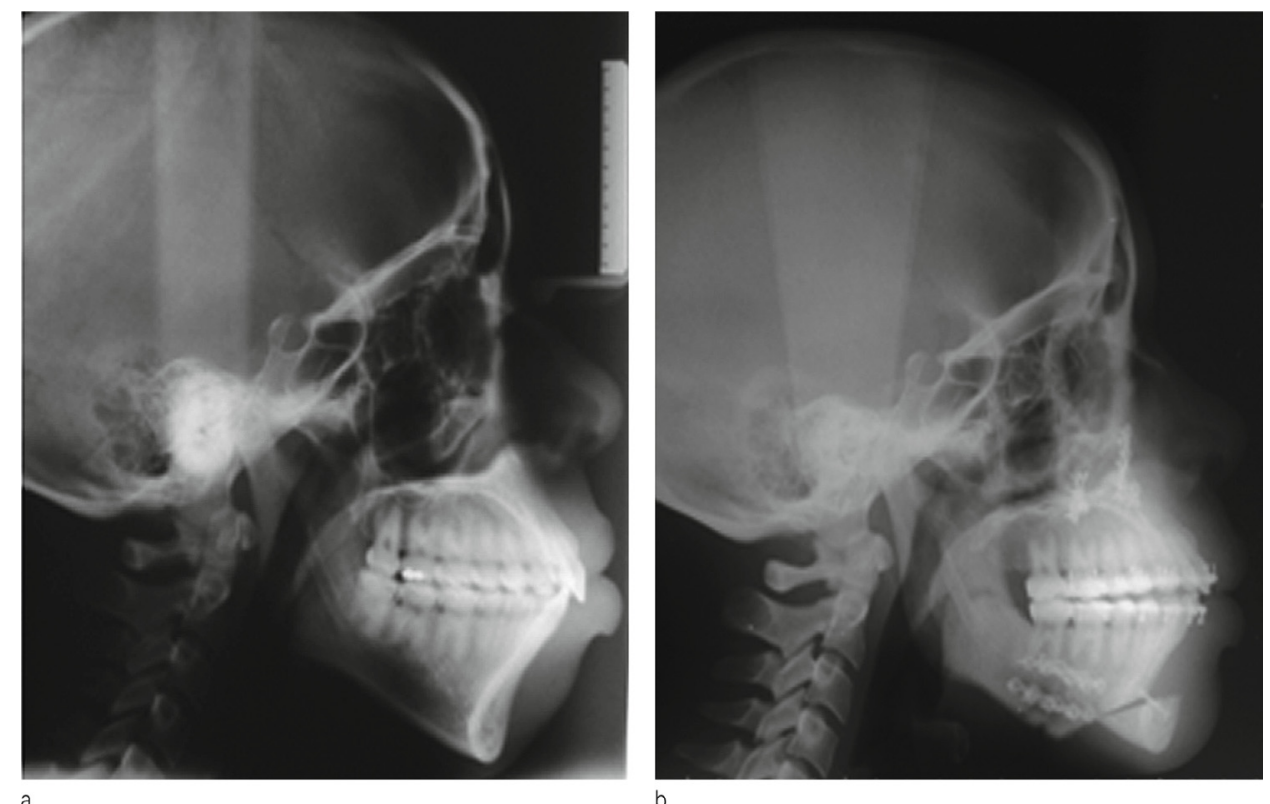

Figure $18 a, b$

Lateral teleradiograph (a) before and (b) after orthodontic-surgical treatment.
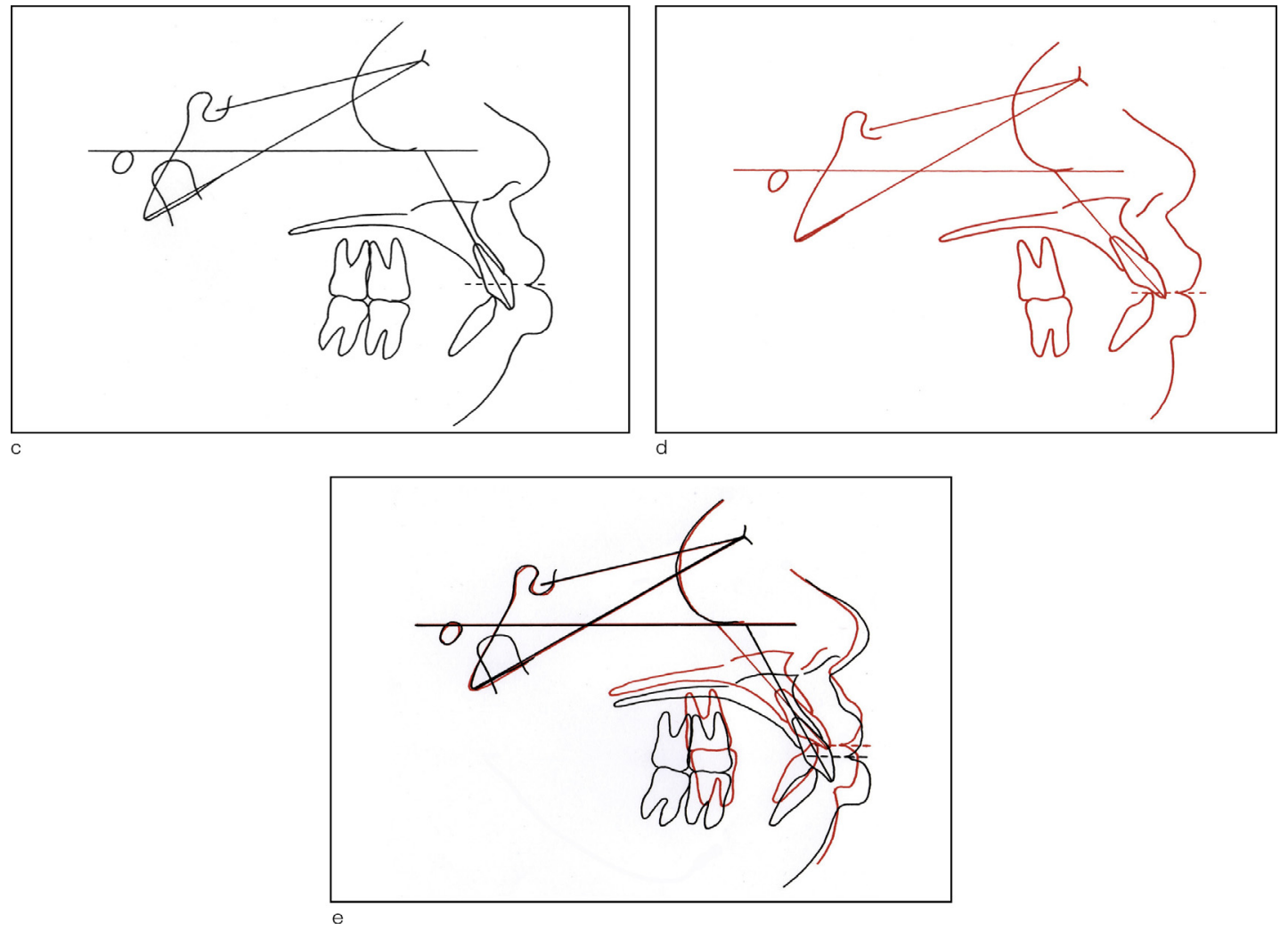

Figure $18 c, d$, e

(c) Drawings at start and (d) end of treatment, and (e) superimpositions in Frankfurt plane. 


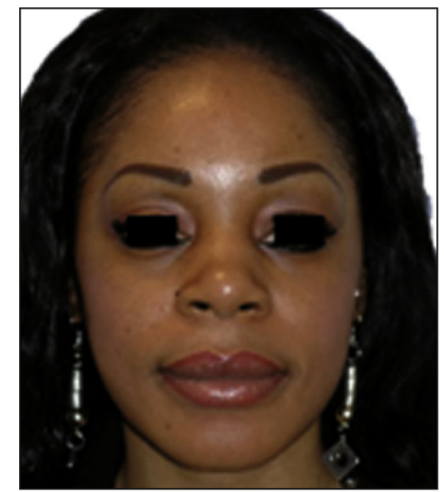

a

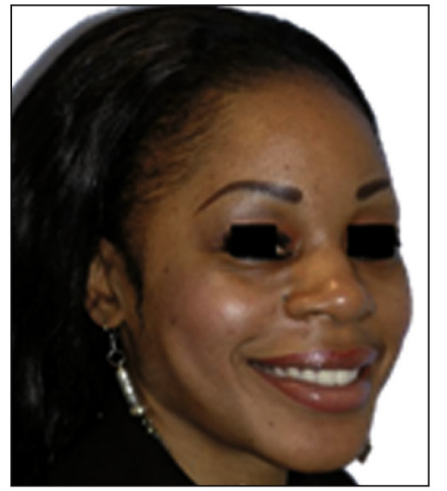

b

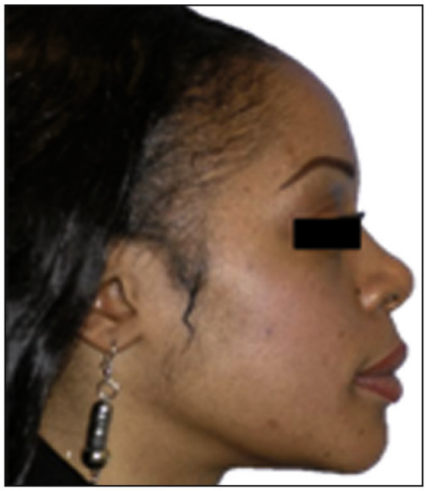

C

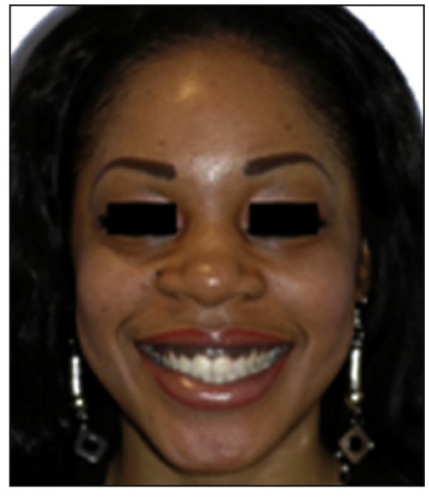

d

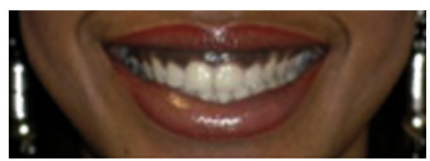

e

Figure 19

$(a, b, c, d)$ External photographs and (e) smile at end of treatment.

- Skeletally, the palatine plane tilted up and forward following treatment. Impaction was greater anteriorly than posteriorly.

\section{CONCLUSION}

Although moderate gummy smile $(<4 \mathrm{~mm})$ can be quite acceptable and esthetically pleasing if the gum is healthy, more pronounced cases are less well tolerated and require treatment.

When gummy smile is basically due to strong vertical alveolar growth at the incisors, isolated orthodontic treatment can provide satisfactory results, especially with the development of bone anchorages, extending the potential of classic orthodontics. Maxillofacial surgery, however, is indispensable when etiology is basal,
Gummy smile was corrected by impaction of the entire maxilla (Fig. 19). related to excessive vertical growth of the maxilla as a whole.

Case studies have shown that, according to the type of treatment, esthetic, dento-alveolar and skeletal consequences differ. It is therefore essential to set treatment objectives in agreement with patient expectations as of the first examination, so as to select the most appropriate form of treatment.

Conflicts of interest: The author declares no conflict of interest. 


\section{REFERENCES}

1. Barbant C, Lallam C, Tirlet G, Attal JP. Étiologies et traitements du sourire gingival. Inf Dent 2011;2:18-24.

2. Borghetti A, Monnet-Corti V, Azzi R. Chirurgie plastique parodontale. RueilMalmaison: Éditions CdP, 2008.

3. Charrier J-B. Chirurgie orthognathique de l'adulte et esthétique faciale. Rev Orthopédie Dento-Faciale 2012;46(2):141-163.

4. Fradeani M. Esthetic rehabilitation in fixed prosthodontics. London: Quintessence Publishing Co, 2004.

5. Garcia R. Le point sur les protocoles chirurgico-orthodontiques. Actual Odontostomatol 1994;187:447-485.

6. Garcia R. Le rôle de l'orthodontiste dans les traitements chirurgico-orthodontiques. $2^{\mathrm{e}}$ partie. Rev Orthopédie Dento-Faciale 1989;23(1):81-111.

7. Lejoyeux E. Orthopédie dento-faciale : une approche bioprogressive. Paris: Quintessence International, 1999.

8. Levin El. Dental esthetics and the golden proportion. J Prosthet Dent 1978;40(3):244-252.

9. Liebart M-F, Monnet-Corti V, Fouque-Deruelle C, Glise J-M, Santoni A, Borghetti A. Sourire, l'incontournable esthétique gingivale. Inf Dent 2011;93(11):14-20.

10. Lockhart R, Dichamp J. La chirurgie du sourire: inté- rêt des ostéotomies maxillaires totales (Lefort I) et segmentaires antérieures. Actual Odonto-Stomatol 2008;242: 179-92.

11. Massif L, Frapier L. Utilisation clinique des minivis en orthodontie. Httpswww-Em-PremComfrodonuniv- Paris5frdatatraitest0745-31938 [Internet]. Available from: https://wwwem-premium-com.frodon.univ- paris5.fr/article/189400/resultatrecherche/1

12. Miller CJ. The smile line as a guide to anterior esthetics. Dent Clin North Am 1989;33(2):157-164.

13. Peck S, Peck L, Kataja M. The gingival smile line. Angle Orthod 1992;62(2):91-100; discussion 101-102.

14. Philippe J. La supraclusion et ses traitements. Paris : Éditions SID, 1995, 96 p.

15. Polat-Ozsoy O, Arman-Ozcirpici A, Veziroglu F. Miniscrews for upper incisor intrusion. Eur J Orthod 2009;31(4):412-416.

16. Polo M. Botulinum toxin type A (Botox) for the neuromuscular correction of excessive gingival display on smiling (gummy smile). Am J Orthod Dentofacial Orthop 2008; 133(2):195-203.

17. Polo $M$. Botulinum toxin type $A$ in the treatment of excessive gingival display. Am J Orthod Dentofacial Orthop 2005;127(2):214-218; quiz 261.

18. Raphaël B, et al. Ostéotomies maxillomandibulaires : techniques. Httpswww-EmPrem-Comfrodonuniv-Paris5frdatatraitest0745-31938 [Internet]. [cited 2014 Jul 1]; Available from: https://www-em-premium-com.frodon.univ-paris5.fr/article/15439/ resultatrecher-che/11

19. Sarver DM. Principles of cosmetic dentistry in orthodontics: Part 1. Shape and proportionality of anterior teeth. Am J Orthod Dentofacial Orthop 2004;126(6):749-753.

20. Sarver DM, Yanosky M. Principles of cosmetic dentistry in orthodontics: Part 2. Soft tissue laser technology and cosmetic gingival contouring. Am J Orthod Dentofacial Orthop 2005;127(1):85-90.

21. Sarver DM, Yanosky M. Principles of cosmetic dentistry in orthodontics: Part 3. Laser treatments for tooth eruption and soft tissue problems. Am J Orthod Dentofacial Orthop 2005;127(2):262-264. 
22. Silberberg N, Goldstein M, Smidt A. Excessive gingival display-etiology, diagnosis, and treatment modalities. Quintessence Int 2009;40(10):809-818.

23. Tjan AH, Miller GD, The JG. Some esthetic factors in a smile. J Prosthet Dent 1984;51(1):24-28.

24. Upadhyay M, Yadav S, Patil S. Mini-implant anchorage for en-masse retraction of maxillary anterior teeth: a clinical cephalometric study. Am J Orthod Dentofacial Orthop 2008;134(6):803-810.

25. Vig RG, Brundo GC. The kinetics of anterior tooth display. J Prosthet Dent 1978;39(5):502-504. 